\title{
Heritage Work: the Preservations and Performances of Thames Sailing Barges
}

\begin{abstract}
'Heritage' represents a series of contested and contingent relationships in the preservation and performance of the past. It is a relationship made all the more complex by taking into account the work that goes into both aspects: preserving what would otherwise be lost, and actively seeking public exposure and support. Work has been central to studies of heritage practices in the context of deindustrialisation: how working identities and communities use or become used in the development of heritage-led regeneration. This article examines what it is to engage in forms of work defined by their personal, community and commercial heritage appeal. It presents a study of those who live and work on Thames sailing barges - historic cargo vessels whose future survival relies on the impetus to preserve them as part of an industrial heritage, and in their fulfilment of a number of (often problematic) performative roles.
\end{abstract}

Keywords: heritage, identity, performance, place, preservation, work

\section{Introduction}

As I emerge from underneath the hull of the 26 metre long Thames sailing barge Repertor, which has been propped up on wooden blocks for repair, I notice someone standing at the shore watching. Ben, the first mate, for whom this barge is both livelihood and home, laughs and explains:

A carpenter that I used to work with on and off taught me the word 'gongoozler' and it's been useful ever since... people who like to watch people work.

The gongoozler is an onlooker, eager to take in the spectacle of these distinctive flat-bottomed, red-sailed vessels and, moreover, the process of work and those who work on them - preserving, maintaining and preparing the barges for sail. 'Can I come aboard?' calls the gongoozler. The first mate politely responds that it would not be safe as this is a construction site, and so they continue to watch from the shore. The interaction comes up again in conversation later, and it is clear that Ben is frustrated by the imposition: 'it's no fun fielding questions when you're knee-deep in shit trying to drill something!' It is a frustration Ben has to live with.

From their development in the early $18^{\text {th }}$ century until the end of the Second World War, Thames sailing barges were responsible for most of the transport of goods and materials into and out of London. They carried brick, coal and other cargo. In one direction 'Stackies' carried hay for London's horses, and in the other, barges returned manure from the city to the fields. The barges were designed to navigate the narrow and shallow waterways that fed into the Thames estuary, and at their peak, over 2,000 vessels covered a working area that stretched the east coast of England. Their end as working cargo craft came with the development of motorways and the articulated lorry. The skeletal remains of many barges now line the banks of these waterways - a visceral display of the decline of their trade. Today, approximately 30 wooden or steel barges survive, many of them resurrected by enthusiasts, trusts and charitable 
bodies, who keep them going by providing pleasure charters, and participating in races and regattas. Their continued existence, and their preservation, not just as sailing vessels but also as places to live, relies on these activities - on being seen.

The figure of the gongoozler is symptomatic of the wider issues at stake when engaging in forms of work defined by a 'heritage' appeal. The roles and trajectories of the barges and bargemen $^{\mathrm{ii}}$ examined in this article reveal what it is to live the way of life you preserve, and the challenge of performing an historic identity while also needing to make a living, or carve a home out of an object of historical fascination. I outline the political, commercial and community interests that construct the character and experience of this 'heritage work', and explain how these affect the motivations of those working to preserve and perform a heritage, as well as those observing such labours. By foregrounding the attachment and meaning applied to workers, their working practices, and the industrial objects that have been or could be lost to the past, I highlight the centrality of work in conceptualising and responding to social change. To understand how work becomes 'heritage', the lived experience of this process, as well as why the working past has a present appeal, I investigate a place in danger of losing the working practices and products that were once central to its identity, and which have guided approaches to remedying this loss. This requires engaging with a range of issues: the complex temporal and spatial relations that must be negotiated when drawing on the past; the challenge of ensuring future prosperity in a changing socio-economic landscape; and the interplay of what is remembered, projected, required of, and embodied by workers and objects that come to represent hope and fear.

In 2015-16 I carried out a series of interviews exploring the relationships of place, memory and work in the town of Faversham in Kent, UK. Faversham has developed a strong sense of its maritime 'heritage', as a shipyard town from 1916-1970. Previously, it had been a key port on the 'barge coast'; Faversham Creek acted as a supply and maintenance point for the barges when they were in trade (indeed a number were built there). It remains a key port for the repair and restoration of re-purposed barges today. In Faversham, the negotiation of the past, present and future is an active process; regeneration plans are still being debated. Questions of what should be preserved and how visitors might be attracted to the town reflect competing notions of place (historic and current), and the issues raised in a regeneration plan framed in terms of bringing 'work' back to the town arouse concern about work for whom and to what end. The Thames barges play an important role here as the representational model for what place and work have been, and could be. I examine the negotiated processes of preservation and performance engaged in by those who own and work on barges, as well as by those who attempt to regenerate the local economy through their appeal. My argument is that ideas of 'heritage', of 'traditions', and of individual and collective work-centred identities, do not only create the conditions for action to facilitate a viable future; they also reinforce an acceptance that the work of the past can only return as part of a new narrative - an identity valued precisely because it is of the past.

\section{The Politics of Heritage}

Though ostensibly backward-looking, 'heritage' is conceptualised through the needs and conflicts of the present, and acted upon with the future in mind. As such, its cultural value and decisions about what to preserve and exhibit, are context-dependent and produce a range of dissonant meanings and interpretations. Indeed to have any value, 'heritage' must transmit what Graham (2002: 1007) describes as a narrative of 'timeless' group identity and, 
simultaneously, be adaptable to the 'particular social and intellectual circumstances' of the situation in which it is invoked.

The implications of this temporal flexibility have been central to academic concerns about the social role that heritage plays. In what became termed the 'heritage debates' of the 1980s, critiques were voiced warning about the political power that an appeal to the past can wield: framing knowledge of both past and present, contributing to the commodification and trivialisation of the past, or weaponised to promote collective identities and understandings (see Hewison, 1987, Lowenthal, 1985, Wright, 1985). In later research (often in response to these approaches), the politics behind the construction and uses of heritage were reframed to emphasise the possibilities. For example, an appeal to heritage could protect threatened identities, communities and ways of life. An exhibition of community heritage might require constructing a marketable story to attract visitors, but it can insure against the loss of identities or traditions in the face of social change, and strengthen the fight for continued representation (Macdonald, 1997, see also Samuel 1994).

Heritage has also been drawn into theories of broad conceptual shifts, complicated as it is by being both of time and of place. Urry (1996) argues that public and political interest in heritage has been part of a wider 'temporal turn', an understanding that time and memory are embedded and embodied in actions, things, places and experiences (see also Heller, 2001: 103). To Samuel, examining how the past is exhibited requires understanding that preservation is not just an act but the beginning of a process which, 'even if it is intended to do no more than stabilize, necessarily involves a whole series of innovations' (1994: 303). The preservation and exhibition of the past produces as much as it expresses, and processes of restoration complicate this further. Heritage objects are, to Laurier (1998: 40), 'time-scarred'. Acts of restoration begin at a certain point in the life of the object, and the restorer's role is to re-create a version drawn from another specific point in its timeline. Restoration, in this sense, creates time for an object - extending its lifespan, and creates $a$ time - turning it into a 'period' piece, though one that says more about the present period than the past. Such innovations tend to 'destroy some cultural traces, even as they preserve others' (Desilvey 2012: 260).

Dicks sees the rise of local heritage museums and centres as indicative of a 'turn to place' where the community being celebrated is more an aspirational idea than a reflection of existing social relationships. More than protect local identities, they can reshape a place. Performing a heritage allows multiple groups to lay claim to it. Heritage enables people to preserve an identity and empowers communities against change and loss. However, heritage also allows those observing and promoting the performance of a heritage - tourists, companies, local councils - to buy and sell a concept of 'authentic' locality. As such heritage practices can work against the very identities they were set up to safeguard, reproducing them as 'local colour' that is highly managed and sanitised (2000: 44). For Lafrenz Samuels (2010) this territorialisation of social experience depoliticises the social problems and changes to which heritage is seen as the solution. Places can become destinations, 'required to play quite distinct roles in the imagination' (Dicks 2003: 49), and ensure that what they represent becomes something firmly past. The touristic appeal of this 'staged authenticity' as MacCannell (1999: 106) puts it, is symptomatic of what visitors feel they have lost; a changing socio-economic environment might have stripped them of relationships to craft and community, but it is still possible to experience it through the lives of others. This othering has the potential to project 
'authenticity' retrospectively, by producing a cultural-temporal shift in our understanding of both past and present. The act of visiting a heritage attraction promises access to older, more 'authentic' socialities not available to visitors in their own lives.

The contestations that anchor the idea and practice of heritage are mirrored in discussions about the nature of representation, and the self-conscious and critical negotiation of cultural identity (Smith and Campbell, 2011). Dicks notes that by thinking of heritage as a form of communication we 'begin to map the various social, cultural and economic relations' that govern it, understand how heritage is produced and consumed, and how its meanings are encoded and decoded (2000: 75). For Smith, its discursive nature means that heritage actively works. It is both a cultural practice and a process that 'engages with acts of remembering that work to create ways to understand and engage with the present' (2006: 44). The 'cultural work' that heritage practices do can reinforce both what she calls an 'authorised heritage discourse' (that of 'institutions and experts, grand narratives of nation and class'), and the 'dissenting' discourses and alternate uses of heritage that challenge it (2006: 11). Heritage is then political, both in the sense of a complex temporal-spatial dynamic underpinning representations of identity, and as a language through which we speak about how and why we do the things that we do.

\section{Heritage and Work}

A prominent way to operationalise this complexity is through identities of work. Studies have frequently taken deindustrialised places and communities, and more broadly the changing face of work, as their focus. As Dicks (2000) notes, from the 1980s local authorities were often encouraged to view ex-industrial places as having 'cultural assets' that could be utilised for leisure-led regeneration. The former mining communities of South Wales that she studied were sold to potential investors as having a rooted 'labourism', something inherited in the experience and memory of the working and political culture of the past, and a trait that could be the basis for new opportunities in production and regeneration. In Strangleman et al's study of former mining communities in the North East of England, they found multiple examples of this process. In trying to bring new investment into the area following the end of the mining economy, councils promoted an image of local people as 'a large pool of skilled and semiskilled labour' with 'a strong work ethic', 'proud and hard-working, energetic and friendly' (1999: 5.1). They had a 'natural resilience and adaptability' (1999: 5.4). Historic working identities now lost were reduced and rebranded. Reinforcing a positive characterisation of the miner supplants the work of mining itself - now firmly in the past, and with it industrial modernity - its occupations, communities, ideals and cultures.

For Dicks such practices opened the way for 'heritage' to become a solution to the changing nature and loss of working identities in the latter decades of the $20^{\text {th }}$ century: a 'heritage enterprise - celebrating traditional cultural identity at the same time as embracing a forward-looking economic identity based on the obliteration of the old' (2000: 28). A tourism that constructs the identity of a community or place in this way does so through multiple lenses: 'as a commodity to market... a cultural arena in which meaningful connections can be ignited between past and present'; it creates distinctions between "here" and "there"... a timeless, other place' that can be visited (2000: 241). Others are less concerned. MacDonald (2013) argues that we should not necessarily find the relationship between market and heritage 
'unsettling', or assume that just because something is bought and sold it somehow becomes 'inauthentic'. For Strangleman, an opportunity to present working-class voices, to hear and see the 'ways people are embedded and become embedded in their work', can provide 'a sense of presence and ownership of work in working people... to have a say in what was done and done to them' (2011: 156).

In this vein, some have focused on the development of industrial museums and the increasing allowance given to narratives of work and working-class experience. This includes the potential of such places to create a productive future dialogue, as well as barriers to the realisation of this potential (Wallace, 1996). Smith argues that such sites are not simply there to 'sooth social distress at the loss of industry', provide economic compensation, or 'titillation' for a tourist market. Instead, visitors are often critically engaged because they are the very people being represented. In other words, heritage underwrites 'a self-conscious sense of class and regional identity' (2006: 196). In her work on visitor reactions, Smith looks at how 'the act of preservation was not so much the visit to the place, but rather the act of passing on memories, family histories and work experiences'. These interactions may be triggered by a place, an object, or a reconstruction, but were used as an educational tool: 'knowledge and values were consciously considered, reaffirmed and validated' (2006: 214). This applied to what is being preserved, as well as what is performed in such a setting. The visit itself is a performance, a ritual engagement with a collective past, a fresh re-telling and re-negotiation of working identities as they relate to family life, community, class and place (2006: 235).

For Dicks however, some performances that go into these sites are more problematic. Heritage sites intend for workers' voices to come through, based on principles of interpretation, interactivity and personalization. However, this has led to a presentation of history that emphasises the experience of the individual over, or as a representation of, a collective narrative. Drawing on the experiences of former workers who became tour guides of the sites they used to work, she examines the demands placed on them in the dual role they perform for tourists. Firstly, they are ex-workers, which reminds visitors that a way of working and living has been lost, and that political forces outside of their control determined their fate. Secondly, they are guides who are in control as representatives of a vibrant culture, and who act autonomously by doing the work of sharing their story. This duality presents a contradiction for the guide: "workers cannot perform themselves as "here and now" when heritage frames them as archaic' (2008: 438). They substitute their own story and experience for that of their (lost) industry, minimising the conflicts that created the situation they are in, as well as those that would have defined their working lives.

The relationship between heritage and working identities has been central to the debate on what heritage is, does and could be, reflecting the contested and contingent nature of its applications. The study of relationships to work has provided frameworks for exploring heritage as an act or process that is located, representational, personal and political. However, the case of the Thames barges provides a different set of circumstances for viewing this relationship. Although barges, as industrial craft, represent a way of working now lost, the critiques levelled at preservation and performance in other deindustrialised settings do not apply here. The barges are neither fixed in place, nor detached from place-based identities. The bargemen are subject to forms of objectification and representation that they may not choose, yet there are also forms that they actively embrace and reproduce. Indeed, most bargemen 
entered the trade with barges in their current roles, so this cannot be a straightforward story of protecting against personal or class losses. The case of the barges sheds light on a way of working with heritage at its centre, by highlighting what work and heritage become in this configuration.

\section{Methodology}

Work, as Studs Terkel (2004: xi) reminds us, is about a search 'for daily meaning as well as daily bread'. 'Heritage work' is no exception, but provides a case whereby what is meaningful and what enables survival exist in layered narratives of personal action, passion and intervention, as well as the historic, collective and cultural meanings attached by others. To explore the implications of this relationship in Faversham, I conducted a series of 25 interviews that encompass the range of narratives and stakeholders involved. ${ }^{\text {iii }}$ These included oral histories with those who own, volunteer or have worked on the barges. The telling of a life story, just as with the history of a place or an object, involves a desire to preserve and protect against loss; it is performative, affective, innovative and 'works' to achieve an end. As such, oral histories provide an approach that explicitly explores the interaction of lived experience and longer-term processes of social, economic and cultural change.

I also held discussions with other parties with a stake in the history and fate of the vessels. For example, with campaigners utilising the image of the barges for community and tourist-led regeneration (reflecting Faversham's current transition from an ex-industrial and economically-deprived constituency to a leisure-based regenerated waterfront). Additionally, I consulted people working in maritime trades intertwined with the history and trajectories of the barges, as well as life-long creek-side residents. The first set of interviewees were recruited through my participation in Picture the Creek, an event held in Faversham in September 2014 that invited people to share photographs and memories. ${ }^{\text {iv }}$ Snowballing was used to expand the initial sample.

In the following sections, I draw on this range of perspectives to examine the lived experience of heritage's social, cultural and economic relations, and to consider those embedded and embodied in the realities of work - in personal, familial, community-led and commercial visions and costs. I explore the politics and practices of preservation and performance to look at the complex relationship between heritage and work as it is actively (re)framed by those relying on the barges' survival.

\section{Preservations}

The questions of what and when to preserve, and of how and why it is justifiable and important, are at the heart of the rationale for heritage practices and the debates that surround them. In the interviews, what it means to preserve is articulated through interwoven relationships between the barges as objects, the lived experience of residency and work of those who own them, the construction of present working identities and the reconstruction of those past. Through this interplay of life, work, heritage and identity creation we can explore the complexity of preservation as an act that is simultaneously personal and social; similarly, the relationships to work that develop in a heritage context are revealed through the examination of preservation practices and motivations. 
Many barges still afloat are well over a century old, which presents challenges for their upkeep, especially when bargemen make them a permanent home. 'They weren't actually built to last as long as they have', notes David, owner of Repertor and its former resident:

They were built to last as working entities probably 20, 30, maximum 50 years I suppose, and some of them date back to the latter part of the $19^{\text {th }}$ century so they've really long outlived their notional life.

The preservation of these barges is complicated by this desire to extend the life of something designed to be temporary, a complication that requires management. Indeed, many barges were lost through misguided attempts to 'patch them up', rather than deal with bigger, structural issues. To keep the barges working is to keep them on the water, but water is an unforgiving environment. As Steve, owner and resident on Greta explains, 'with the wooden barges it's the fresh water that rots the wood, whereas with steel barges it's more the salt water'. The changing seasons also contribute to their deterioration:

In the winter what does the harm to the wood and everything is the frost. So if it's getting wet and it freezes, it expands. It blows the paintwork off, pushes the wood apart.

They require constant maintenance over the course of a day and of a year - keeping the temperature up, servicing the equipment, removing scale from the hull, painting, replacing what cannot be kept going any longer. As Tim, a shipwright and former owner of Decima remarks:

One sees these sailing barges out in the middle of the summer and it's all wonderful, but come down here in the middle of winter and get under a sailing barge in the freezing cold to scrape the bottom, and it's a different side of the coin.

It is hard work, not made easier by the desire to use 'traditional' methods, as Ben of Repertor describes:

Everything's done in a kind of traditional sense... you're sticking planks with horse shit and boiling tar on felt, and a lot of things are done by hand or by sheer weight.

Neither is it helped by the cost and difficulty of sourcing materials, as Frog, owner of and resident on Orinoco complains: 'Just buying the iron spikes to spike the barge together... $£ 300$ a box, right, of seven inch spikes... well, you use a box up in a morning'.

Frog's position is even more interesting because he is not just living on the object he is trying to preserve, he's also raising a child on something old and prone to problems: 'some nights you get back and the power's gone off and it's dark and the fire's gone out and it's cold'. Such issues are easily outweighed in his mind by the quality of life he can offer: 'you've got the cows going past, the tide coming in with the boats... I've had some lovely evenings out in the Swale with just me and her'. Toby lives on Ironsides with his partner and son. Ironsides had been out of action for 13 years when they 'stupidly said yes' to taking on her restoration 
'from just a metal box' to a barge they could live aboard and sail. 'It's quite basic but it's lovely' he insists:

Whether our little boy appreciates it when he's older I don't know yet... he doesn't know any different but he's got the boatyard to run around which is excellent really and everyone in the boatyard's super. It's like an extended family.

As well as having their children play together in the yard, Toby and Frog agree on why they put up with occasional discomfort: a purpose that combines the need to provide a home, with a desire to preserve an historic object. David of Repertor, whose own children were raised on or around a barge, echoes this sentiment:

Somehow or another we've got sucked into this idea that these vessels are part of our maritime heritage and they need to be looked after and we are, as owners, in trust to deliver them to the next generation.

As if to prove a point, David's son Ben ties this sense of custodianship to the uniqueness of the Thames barge: 'if you get down to the basics of it, it's fucking cool... huge amounts of sail that can be sailed with two people'. Custodianship here holds two meanings: 'generations' drawing together a sense of passing something on to one's own children, and to an imagined future society.

Steve of Greta relates the importance of the barges to their place in an industrial timeline: 'they were the last working craft under sail in Western Europe'. In working to keep the barges sailing, their former end as cargo craft is as significant as their feared future demise. Colin, former owner and ongoing advocate for the restoration of Westmorland, is keen for me to understand:

She is the last of the brick barges. I mean for a person like yourself you might think one barge is the same as another one but they're all designed to do different things.

This sense of 'the last' or an 'ending', extends beyond the barge itself. For some, the primary thing being preserved is not the barge object but aspects of barge life. With the imagined end of the barges comes the fear that a particular set of skills will be lost. As Toby emphasises:

Sailing's quite a specialised thing... to sail one you're supposed to do a Barge Master's ticket and there's an awful lot to know about it... it's just keeping that knowledge going because it's not actually really written down.

A way of working but also a way of life is viewed as under threat. In Tim's words, the aim is 'to make sure they keep on doing what they're doing, what they should be doing, what they've always done'. This understanding of their permanence complements the importance of the barges' temporariness, however counterintuitively. For Ben, 'to sail on a barge is to in some way understand how maritime trade did happen', a sentiment shared by those who have been 
out sailing. Lyn, a creek-side resident who grew up seeing the barges in the cargo trade, considers going out on remaining barges as getting 'a taste of what life was like'. For Alan, who lived on board a Thames barge during his university days in the late 1970s, and who now builds and restores wooden boats, work connects past and present, and becomes the life of the barges:

They're working; they're not just museum pieces. You know, they float, they sail... you don't see many examples of history still alive.

Ben is reflexive about his life as a working bargeman today compared to the images of the past that the barges conjure:

I make no bones; it would have been fucking hard and in the wintertime it would have been shit and cold, and life expectancy wouldn't have been great, working conditions at times would have been piss poor... you were at the behest of the elements... It was what it was.

Ben is also critical of the current role of the barges and the work of being a bargeman: 'this community seems to embody other things now'. The past identities of barges are rewritten and enabled by the work of preservation and the lives carved out on them. This rewriting partly emerges from the means required to keep the barges going: exhibition and performance.

\section{Performances}

The owners, workers, volunteers and advocates interviewed stressed the importance of barges and bargemen in both performing an historic identity, and in facilitating a performative experience for passengers. Their work is exhibited for public consumption, with consequences for the bargemen and their ability (through funding and promotional opportunities) to work at all.

The day-to-day work of maintaining the barges as sailing vessels and homes inevitably requires capital, as Steve notes:

You need a very good income... or a lot of time and preferably both... the old quality of life's quite good but the old bank balance ain't at times.

With no viable cargo industry, most owners fund the barges by hosting passengers. This seasonal work requires that owners adapt how the barge is used and where it is moored to attract different audiences. Preservation work is a springtime activity, aiming not just to repair regular wear-and-tear but also to prepare the barges for paying customers. For those who make their living primarily through chartering and sailing trips, work from May until September is dictated by the nine dates of the barge racing calendar.

The races date from cargo trade times, as Colin explains:

They started as a rivalry between companies... a company would lay down the gauntlet and say, "I'll race you"... they wanted to fly their flag. 
As the races became a regular activity, so the barges transformed from vessels that delivered goods and materials, to vessels that could also race. 'It's like motorcar racing,' suggests Colin, 'it develops the engine... Likewise with the sailing barge, they realise that if they made the sprite longer they will go faster'. This had practical implications beyond friendly rivalry, that developed the barges for both purposes: 'if you were alongside the quayside in London first you'd get unloaded first'. After being retired from cargo work, some barges were kept on as racing craft by individuals and trusts and, as more were restored, racing became their primary activity. Den saw this shift first-hand, having worked on the barges while they were in trade (before, appropriately, becoming a lorry driver). Now retired, he volunteers as crew on Repertor:

She ain't like a working barge; her gear's a lot bigger and heavier... They're entirely different things, racing them. We would never sail like they do. Not on trade.

Ben though, is keenly aware of the disparities between the old 'trade' and the new:

I think a lot of barge skippers up until the ' 40 s or ' 50 s would have a conflicting relationship with the idea of the barges being used... you know, as passenger yachts really, which is what they are now. The cargo's changed!

In this sense the maintenance of the barges, and by extension their historic identity, is as much a production of a new working identity as it is an attempt to preserve the old. Their continued survival relies on them not being the cargo vessels of the past, but maintained instead to a different specification. The races, or as Ben puts it, the 'pageantry of sail', have become not just the primary source of their current working identity, but also a substitute (despite these changes, and without knowledge of them) that satisfies customers' desires to experience their past - one that is both enjoyable and achievable. Sailing both re-enacts the cargo trade and routes, and becomes 'an adventure', to use the words of Peter, an ex-shipyard worker who volunteered on the restoration of a number of barges. The past is experienced in the interaction with and observation of contemporary 'bargemen', what Connerton (1998: 74) describes as the embodied 'choreography of authority' of their actions, gestures and the stratification of roles. It is experienced in the activity of sailing under expert guidance.

The audience for this experience and adventure includes people over 50 years old with disposable income, young families looking for a day trip, and barge enthusiasts. 'In some cases,' notes David, 'people come because they're knowledgeable and interested in traditional sailing methods. In other cases they just want to come along and watch'. For Frog, the inexperience of charter passengers is a seasonal anxiety:

Some people don't know what they're doing, some people do but you've got to take it very seriously because you're sailing around in an 80 tonne barge.

Frog has avoided regular chartering for this reason (though financial needs never permit a way out completely). As with the work of preservation, the work of performance is dependent on 
the weather. Races cannot proceed in some conditions and paying customers can be difficult to appease in such situations. Here the need to fund preservation through performance comes up against the practicalities of preservation itself:

The barge ain't brand new, it's got its wants... With a wooden barge, if you push it you'll make it leak.

Sailing a barge incurs costs beyond wear-and-tear - crew, fuel for the engine if there is no wind, catering, mooring - and this means often having to make difficult decisions about whether to sail at all. Logistically, there are also costs, including the physical labour and time spent getting to races or disembarkation points. This can take anything from two hours to two days sailing, and the destination can be anywhere along the South-East coast of England and into London. There are also costs to having people in your home, as Ben describes:

For half the year the jobs that we have are static so you can live on there quite easily without it kind of impinging, but [during the summer] we have jobs on here... it's a bit more difficult... packing all my stuff away.

Frog's daughter is not spared from the requirements of creating space for performance: 'all the toys, all the clothes and everything, it all gets tidied away.... it is quite a lot of work'. More important, however, is the presence of strangers where he shares his home with his daughter:

It's quite strange really... you have 12 people a lot of the time that you don't know and they are literally in your home.

Trusting the unknown is worked together into the logistics of being responsible for various parties - his daughter, the barge, his customers.

After the summer, a new set of challenges arise. How to fund the barge without the attraction of the races or good weather? Those who have made enough money over the summer, or who have other work, can simply moor up for the season and place protective covering over the barge to keep out the weather. This does not put them out of the public eye, as Frog observes of his location:

Hoards of families with their dogs. They love it, don't they... and they're walking down here because they think it's all quaint, don't they: rotten boats and barges.

Those who require an income throughout the year enter a further phase of performance for new audiences. Whereas a barge in sail may only be able to carry 12 passengers, the larger vessels can hold 50 to 60 people for a static function. Some take a general approach, accepting bookings for private parties and corporate functions (this also happens between races during the summer). However, the type of work that is taken, and the public roles that the barges take on during this period, often depend on where the barges can be moored: they serve as tea rooms, nightclubs, art galleries and recording studios. 
To raise extra income on Repertor Ben held a series of film screenings on the barge during two winters moored at St Katherine's Dock in central London. These events were designed to bring in short- and long-term funding: to 'raise the profile of the barge and the barges as unique, maritime London heritage; you know, come and see a barge'. While the screenings were sold out, and the audience was intrigued by the unusual setting, it did not translate into future bookings. The problem was that the films attracted a different demographic from the barges at sail, people in their 20s and 30s without the income to follow up and, being in central London, with plenty of other options for things to do. Echoing Dicks (2003) and Lafrenz Samuels (2010) he is reflexive about the nature of the 'attraction' he is promoting, and how getting across the heritage of work can feed into a place-based heritage. Ben took issue with the location in terms of the cost of living and working, and the requirements of performing an historic identity where the barges are treated as a novelty object:

Sitting in St Katherine's being used as a backdrop next to a public jetty. Like we get half price rent here because we're heritage boats... it's because we're eye candy, it's that intrinsic value that it brings to... or credibility, authenticity of this made-up marina... along with the fucking Dickens Inn it gives it that sort of air of like historical value.

He is aware of the role that his barge played in exchange for a central London mooring that is a good place to live and for public exposure. Maintenance work was forbidden under the St Katherine's contract as it is surrounded by offices, residences and restaurants. This is a place for the finished product. The reality of the continuous work required to maintain these 'finished' products is detached from their appeal in this setting. The requirements placed upon the vessels and bargemen in the spaces made available to them has, argues Tim, affected the reasons for taking on barges:

An increasing number are being bought by people who don't really have a particular love of sailing. They might be attracted and like the idea of owning a sailing barge but they really are more interested in owning it, tying it up in some dock in the middle of London.

Situation is central to the nature of the performance. As Ben concludes:

I mean it depends on location, doesn't it, as to how you're looked at. If you're looked at in a residential setting then you're looked at as a backdrop. If you're looked at in a working setting, I guess it gives people a good sense of community and to know that something's happening.

Here, Ben hints at another issue that has placed the Thames barges at the heart of debates about the historic identity of place, and the kinds of objects and activities that become their proxies.

Faversham, as a port on the barges' former and current trade routes, has utilised the image of the barge in attempts to regenerate the creek-side area of the town. Whereas in central London the barges are meant to be seen and not heard, in Faversham what can be seen and/or heard are the terms of debate over the future of the local economy. The image of a barge is a mainstay of materials produced for tourists - promotional posters and brochures, badges, 
keyrings, mugs and coasters. The largescale return of barges to Faversham has been viewed by all organisations tasked as the key to success. Moreover, the issue in Faversham is whether such a regeneration will imitate St Katherine's, or whether the work of bargemen should be emphasised. Local artist and campaigner Nathalie sums up a sentiment expressed in many of the interviews about a specific barge that was rebuilt at Faversham, before being relaunched in 2011:

The restoration of the Cambria. That was a massive magnet for people's interest... now it's gone because it can't stay anywhere... it was restored here!

The idea that the barges should be worked on is in the rationale guiding local regeneration campaigns, and also that bargemen working is what people would travel to see. Sue, chair of the Faversham Creek Trust, argues that when more 'work' (specifically, maintenance and repair) was carried out at the quays in Faversham:

People used to go down... to look at people working on barges and they'd come and stand on the footpath... and they would look at people working or just pottering about, and they would just look at the boats.

Campaigner Brenda thinks that people would 'go down just to watch the guys working... people love looking at boats and messing about on boats'. Here, the complicated relationship between preservation and performance is built into the conceptualisation of a place, with the bargemen acting as advocates for an identity that they may or may not recognise. This framing, like other ex-industrial sites explored by Strangleman et al (1999) and Dicks (2000), imbues the current bargemen with the historic (and saleable) qualities of those in the cargo trade; it also projects a narrative equating work in trade with the practices of restoration and repair, and the experience of work (in differing forms) to Faversham itself. Moreover, for shipwright Tim, the idea of creating a hub for barges and repair-work in fact threatens to 'take my work away from me' by adding competition to an already precarious way of working. If the regeneration plans come to fruition, the willingness to work would be dictated by the need to earn a living and find affordable moorings, as well as the ability to carry out repairs unhindered. People 'messing about on boats' is not ideal in this regard. Equally the use of the barges and bargemen - their image, their working identities and day-to-day lives - as promotional material, a desired end to a political process, a way to reinvigorate a community - means that whether the bargemen are willing or not, their barges will take on a role dictated by a performative identity.

\section{Discussion}

To preserve one must perform an identity that is preservationist. To live the life of a bargeman and labour in the work of preservation and performance, one must locate where in time that life begins and ends. This involves negotiation. An identity of historic trade and work must be suited to the needs of a current trade, recreated through an adaptation that, rather than being viewed as less 'authentic', provides an experience for workers, passengers and watchers that frames authenticity through the living barge. Preservation is understood by those who work and those who watch (or those enticing potential workers and watchers) as an ongoing process. Because 
the barges have changed their purpose, and evolved as craft, they have continued working and representing the past lives from which they evolve.

The maintenance work now undertaken, and the chartering work it aims to attract, are distinct from the trade that the barges engaged in historically. Heritage work is, in this sense, old but also new: it is presented as historic, and it utilises 'heritage' methods, skills and imagery to frame and justify an altered relationship to the past that allows the barges to survive when being 'true' to that past would not. The 'lives' of the barges reflect Laurier's (1998) understanding of restoration: they are simultaneously periodised to a point in the past and expected to be experienced or relived in the present. As Herzfeld argues, the appeal of 'traditional' forms of work, indeed tradition itself, is created and reinforced in the production and exhibition of 'traditionalizing' objects, and by framing those who produce them as tradition embodied (2004: 27). With the bargemen, this process also requires a lived commitment - a way of life that relies on public exposure, a necessary intrusion, a display and adaptation of identity. This identity needs to be seen by all parties as of the past, while negotiating an environment that imposes a range of present restrictions and expectations. Today's bargemen lack the infrastructure, community and relationships of bargemen past, and so the embodiment of a retrospectively applied ideal of work gives them an ambiguous and malleable status in the present.

Heritage as a concept and a practice 'innovates' (Samuel, 1994), but through performance as much as through preservation - with various ways to destroy as much as it preserves (Desilvey, 2012). Heritage is a key way for people, communities and places to negotiate and communicate their everyday life and collective identities; it is a performance of multiple, simultaneous parts. What the barges show us is that the lived experience of heritage is a working concern in every sense. However, in mapping the relations between heritage and work, the changing nature of work comes into better focus, allowing us to understand how it is connected to identity and place. Heritage allows a renegotiation of the work that once made a place - a sense of skill, value, productivity. What once existed suggests what might yet be again, but with the caveat that this kind of employment (its identities and communities) cannot be reproduced identically. Heritage is a new trade for a new situation that reframes the old so that a town left behind by a changing economy that erased a meaningful identity might have a future through the re-enactment and embodiment of the practices and products of work that once gave it meaning.

\section{References}

Connerton P (1998) How Societies Remember. Cambridge: Cambridge University Press.

Desilvey C (2012) Observed decay: Telling stories with mutable things. In Dudley SH (ed) Museum Objects: Experiencing the Properties of Things. Oxon: Routledge.

Dicks B (2003) Culture on Display: The Production of Contemporary Visitability. Maidenhead: Open University Press.

Dicks B (2000) Heritage, Place and Community. Cardiff: University of Wales Press.

Dicks B (2008) Performing the Hidden Injuries of Class in Coal-Mining Heritage, Sociology 42(3): 436-452. 
Graham B (2002) Heritage as Knowledge: Capital or Culture?, Urban Studies 39(5-6): 10031017.

Heller A (2001) A tentative answer of the question: has civil society cultural memory?, Social Research 68(4): 103-142.

Herzfeld M (2004) The Body Impolitic: Artisans and Artifice in the Global Hierarchy of Value. Chicago: University of Chicago Press.

Hewison R (1987) The Heritage Industry: Britain in a Climate of Decline. London: Methuen.

Lafrenz Samuels K (2010) Material heritage and poverty reduction. In Labadi S and Long C (eds) Heritage and Globalisation. Oxon: Routledge.

Laurier E (1998) Replication and Restoration: Ways of Making Maritime Heritage, Journal of Material Culture 3(1): 21-50.

Lowenthal D (1985) The Past is a Foreign Country. Cambridge: Cambridge University Press.

MacCannell D (1999) The Tourist: A New Theory of the Leisure Class. Berkeley: University of California Press.

Macdonald S (1997) A People's Story: Heritage, identity and authenticity. In Rojek C and Urry J (eds) Touring Cultures: Transformations of Travel and Theory. London: Routledge. Macdonald S (2013) Memorylands: Heritage and Identity in Europe Today. Oxon: Routledge. Samuel R (1994) Theatres of Memory Volume 1: Past and Present in Contemporary Culture. London: Verso.

Smith L (2006) Uses of Heritage. London: Routledge.

Smith L and Campbell G (2011) Don't mourn organise: heritage, recognition and memory in Castleford, West Yorkshire. In Smith L, Shackel PA and Campbell G (eds) Heritage, Labour and the Working Classes. London: Routledge.

Strangleman T (2011) Working class autobiography as cultural heritage. In Smith L, Shackel PA and Campbell G (eds) Heritage, Labour and the Working Classes. London: Routledge. Strangleman T, Hollywood E, Beynon H, Bennett K and Hudson R (1999) Heritage Work: ReRepresenting the Work Ethic in the Coalfields, Sociological Research Online 4(3).

Terkel S (2004 [1974]) Working: People talk about what they do all day and how they feel about what they do. London: The New Press.

Urry J (1996) How societies remember the past In Macdonald S and Fyfe G (eds) Theorizing Museums: Representing identity and diversity in a changing world. Oxford: Blackwell.

Wallace M (1996) Mickey Mouse History and Other Essays on American Memory. Philadelphia: Temple University Press.

Wright P (1985) On Living in an Old Country. London: Verso.

\footnotetext{
i 'Gonzoozler' is a term also commonly associated with the canal barges that once served the inland waterways of the UK.

ii The gendered nature of this term reflects the language used by those in this work, as well as that, historically and currently, the vast majority of those who have participated in sailing the barges are men.

iii I have used participants' real names throughout, having obtained their consent to do so.

iv This event was organised by local arts organisation, Kent Creative: http://kentcreativearts.co.uk/
} 